\title{
Development Typology for Retail Networks in the Russian Federation
}

\author{
O.V. Martynovaa \\ Yu.S. Valeevab \\ a Kazan Federal University, Institute of Management, Economics and Finance, Kazan, 420008, Russia \\ ${ }^{b}$ Kazan Cooperation Institute (Branch) of the Russian University of Cooperation, 420081, Russia
}

\section{Doi:10.5901/mjss.2015.v6n1s3p155}

\section{Abstract}

Under the prevailing economic conditions, retail networks preset the thrust for the development of the trade sector in the Russian Federation. The retail networks develop according to two development types: extensive and intensive. Due to greater concentration of chain retailing, methods of intensive development, such as innovations, become actual in regions of. A timely evaluation of the intensive development of retail networks enables estimation of strategic prospects of their development.

Keywords: retail networks, intensive development, extensive development, innovations, estimation of the intensive development.

\section{Introduction}

Retail networks discharge important economic and social functions (for the state, consumer and manufacturers) by means of engaging foreign investments in the economy, development of the trade infrastructure, satisfaction of consumers' needs for goods, elaboration of business relations. As rule of thumb states, the development thrust for the trade sector in the Russian Federation is preset by retail networks whose share in the structure of the turnover of the sector in March 2014 amounted to 23.1\% of the total sales volume of retail networks. In 33 regions of the Russian Federation, the share of the chain retailers in the total sales volume of the retail trade exceeded the mean level throughout Russia.

At present, retail networks develop, for the most, by means of extension of their shopping space. However, due to increasing concentration of the trade business (about 20\% in a number of regions, while the threshold level is $40 \%$ to $45 \%)$, tougher competition in the chain retailing market, increase and differentiation of purchasers' needs, the necessity to implement the intensive development of the retail networks' services occurs. Moreover, as the Russian Federation has joined the World Trade Organization, it is necessary to shape a comprehensive approach ensuring innovative development of trade structures as a factor of competitiveness for the Russian trade sector.[3]

\section{Theory}

We define the development of a retail network as a process of quantitative and qualitative changes in the retail network's activities implemented in response to factors of the internal and external environment and intended to increase the efficiency of its activities. The qualitative changes in the activities of the retail network appear as an increasing number of retail facilities (increase of shopping space and staff numbers). The development of the retail network based on an increase in numbers of retail facilities by means of construction, purchase, lease of shopping space, franchising, and deeds of merger or amalgamation is considered as an extensive development pattern. The qualitative changes in the activities of a retail network are manifested as increased indices of efficient application of the retail network's resources (materiel, labor, finance) due to implementation of achievement of the technological advance, improved approaches to the labor arrangement and management. Such development pattern is regarded as intensive one. As a rule, the extensive and intensive development processes are to flow simultaneously but to a different extent depending on the conditions of the internal and external environment. Figure 1 represents the development patterns and methods that define them. 


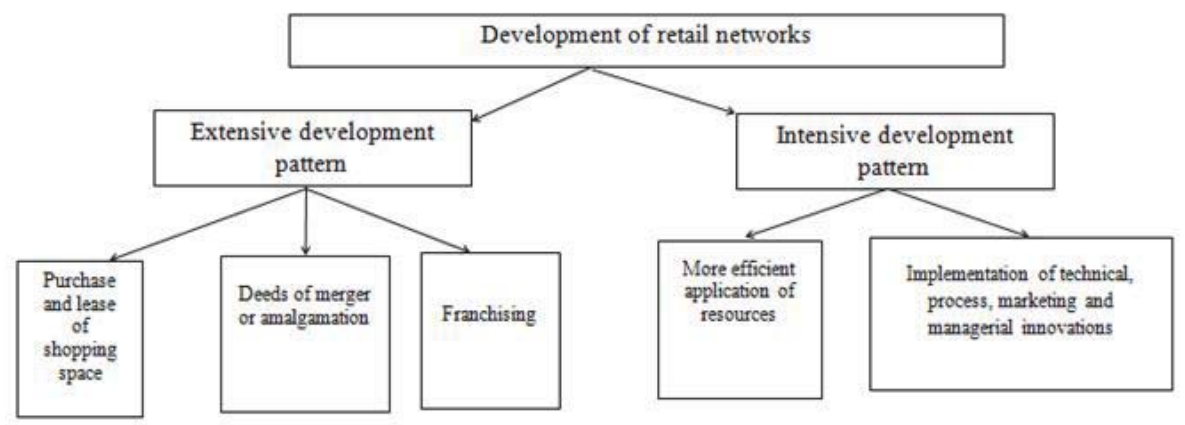

Fig. 1 Development patterns for retail networks

Table 1 represents the factors that influence certain development patterns for retail networks.

Table 1. Development factors for retail networks' services

\begin{tabular}{|c|c|c|}
\hline & Contributing factors & Barring factors \\
\hline Extensive development & $\begin{array}{l}\text { - unbalanced penetration (concentration) of retail } \\
\text { networks in regions; } \\
\text { - availability of the effective demand from the residents; } \\
\text { - availability of government-backed programs intended to } \\
\text { provide the residents with up-to-date shopping space; } \\
\text { - popularity of the multi-format approach; } \\
\text { - expanse of the country. }\end{array}$ & $\begin{array}{l}\text { - greater consumers' demand for quality trade } \\
\text { services; } \\
\text { - increasing competition in certain regions or } \\
\text { cities; } \\
\text { - high prices and lease rates for shopping } \\
\text { space. }\end{array}$ \\
\hline Intensive development & $\begin{array}{l}\text { - antimonopoly regulation of retail networks' activities in } \\
\text { the Russian Federation; } \\
\text { - development of information technologies; } \\
\text { - institutional abundance of shopping space in certain } \\
\text { regions; } \\
\text { - proactive proposal of innovative equipment for trade } \\
\text { facilities by manufacturers; } \\
\text { - poor workforce efficiency inherent for the trade sector. }\end{array}$ & $\begin{array}{l}\text { - poor qualification of the personnel; } \\
\text { - shortage of financial resources; } \\
\text { - difficulties with adapting the innovations to } \\
\text { the conventional approaches to the } \\
\text { arrangement of the retail business; } \\
\text { - poor development level of the trade } \\
\text { infrastructure in the country. }\end{array}$ \\
\hline
\end{tabular}

\section{Outcome}

At the moment, the extensive development pattern is prevailing among the retail networks. This is due to the fact that such subjects of the trade sector have formed in the Russian Federation relatively recently and the concentration level is not high and uneven in terms of geography. Thus, for example, in the cities of Saint Petersburg and Moscow, the penetration level of the chain retailing amounts to 51\%. Nevertheless, in many regions of the Russian Federation, retail networks cover $10 \%$ or less of the retail sales volume. According to a mid-term forecast of the Ministry of economic development of the Russian Federation, by 2015 the share of the chain retailing in the structure of the retail sales volumes will amount to $30 \%$, while in most large cities it will reach $50 \%$. Under the conditions of a high concentration of the retail business, the methods of intensive development for the retail networks' services become relevant.[6]

One of the methods of the intensive development is an augmentation of the application of the retail networks resources: strenuous, more intensive flow of the trade and economic processes facilitates more efficient application of the resources. Saving of means and objects of labor is related not only their increased operation per a unit of time but also to their replacement with more efficient ones. A number of researchers suppose that the basis for the intensive development pattern is the scientific and technological advance and/or innovations. While researching the innovations in the retail business implemented in order to improve the efficiency of the activities, their following features should be taken into account:

- in the trade sector, innovations to the largest extent are related to the occurrence of a new technology or service for its representation or their perfection. Thus, consumers obtain a new or greater value of the service. Innovations in the wholesale or retail business occur not as a result of a research and development but as a result of a certain analysis and/or benchmarking;[1] 
- novelties related to the occurrence of new elements of the trade process or marketing are implemented at trade facilities;

- in the trade sector, innovations are created or implemented, both developed within the sector itself and in other sectors, first of all, in productive industry;[5]

- a large extent of the innovations in the trade sector is borrowed from the foreign expertise.

The notion of 'innovation' is quite properly construed when allied to objects of the trade sector as a novelty implemented for the purpose of improving the efficiency of their activities. Innovations in the trade business manifest themselves as a new format of the service provision by means of implementation of new process, marketing or managerial solutions capable of reducing the costs and increasing the sales volume.

Implementation of certain types of innovations is justified with peculiarities of activities of the retail networks that include the scale of the activities and complexity of the business processes:

- application of a regional expansion strategy facilitates the occurrence of managerial innovations;

- application of the multi-format approach facilitates the development of marketing innovations;

- development of the retail networks consolidation policy entails the occurrence and development of innovations related to logistics flow management, ect.

The innovations are embodied in the increased workforce efficiency, return on assets, revenue per square meter of the shopping space, increased return on expenses and the current assets movement rate.

Let us dwell on the essence of such indices from the point of view of their innovative contents:

- the workforce efficiency is the most relevant index for the intensive development of the retail network's services. Augmentation of the workforce efficiency can be performed by means innovative implements: personnel development, innovative information technologies for the labor automation, etc.;

- the return on assets is ensured by means commissioning innovative equipment that makes it possible to perfect the operations related to sales of goods and customer service;

- current assets movement rate. Current assets of the retail network are represented with the stock, accounts receivable and money assets. At present, innovative methods emerge for the management of such groups of assets, which enables to increase their movement rate. For example, factoring operations are used to manage the accounts receivable, which enable to increase the cash flow rates, to reduce the costs related to the account management and to ensure settlement of debts;

- return on expenses. A positive dynamics of the return on expenses evidences the application of innovative developments in order to reduce certain types of costs of the commercial or managerial nature. Nowadays, retail networks proactively implement novelties, such as power-saving technologies, which enables to reduce utility charges, while new managerial methods enable to optimize the labor costs, and new process equipment enables to reduce the depreciation expenses;

- revenue per square meter of shopping space. An efficient operation of shopping space may be achieved provided the trade facility is complete with up-to-date shop fittings and equipment with a large enough area of the goods layout, application of merchandising approaches depending on the type and composition of the shop equipment.[2]

Due to the fact that at present intensive development patterns become a necessity for a number of chain retailers, a requisite occurs to develop a method for an evaluation of the achieved level of the intensive development and elaboration of strategic prospects.

It was identified in the course of studies of methodical approaches for the evaluation of the intensive development level for economic entities that it is advisable to perform the calculation on the basis of obtained values for indices with preset basic values. Indices for past period, their industry-mean values, relevant indices of competitors, statistic data by leading Russian or foreign companies can be used as such comparative values.[4]

In the evaluation method for the intensive development level of various retail networks adopted by the authors, a virtual retail network is used as a reference where all the indices inherent for the intensive development backed up with implementation of innovations are the best.

In general terms, the algorithm for a ranking of the intensive development level of the retail networks' services can be presented as a sequence of the following stages:

Stage 1. Selection and justification of indices, their calculation. The system of economic indices featuring the intensive development of the retail networks' services is compiled of conventional indices (workforce efficiency, return on assets, current assets movement rate) and supplemented with a number of indices featuring the peculiarities of the trade sector (return on expenses and revenue per square meter). The basis for the calculation is the augmentation rate backed up with innovations for the above indices. 
The indices were calculated according to the following formula:

$\Delta \mathrm{P}_{\mathrm{i}}=\left(1-\mathrm{K}_{\mathrm{e}}\right){ }^{*} \Delta \mathrm{P},(1)$

where

$\Delta \mathrm{P}_{\mathrm{i}}$ is the rate of alteration of the analyzed index due to implementation of innovations;

$\mathrm{K}_{\mathrm{e}}$ is the ratio of effect of extensive factors to the augmentation of the analyzed index that is defined be expertise and alters within the following range:

$0 \leq \mathrm{K}_{\mathrm{e}} \leq 1$;

$\Delta \mathrm{P}$ is the alteration of the index during the accounted period compared to the previous period.

Stage 2. Representation of the indices as a matrix $\left(a_{i j}\right)$, i.e. a table where the lines contain entries with the numbers of the indices $(i=l, 2,3, \ldots, n)$, and columns hold the numbers of the analyzed retail networks $(j=1,2,3, \ldots, m)$.

Stage 3. The maximum value is found and entered into the column of the virtual reference trade facility (max).

Stage 4. The initial indices of the matrix $\left(\mathrm{a}_{\mathrm{ij}}\right)$ are normalized as related to the respective index of the reference trade facility according to the formula:

$\mathrm{Xij}=\mathrm{aij}_{\mathrm{ij}} / \max \mathrm{aij}_{\mathrm{ij}}(2)$

where Xij are normalized indices of the j-th retail network. formula:

Stage 5. For each analyzed retail network, the value of its ranking estimation is defined according to the following

$$
R j=\sqrt{(1-X 1 j)^{2}+(1-X 2 j)^{2}+\ldots+(1-X n j)^{2}}
$$

where

$\mathrm{Rj}$ is the ranking estimation for the j-th retail network;

X1j, X2j, ..., Xnj are normalized indices of the j-th retail network.

The retail networks are ordered (ranged) in the descending order of the value of the ranking estimation. The trade facility with the lowers $R$ value will have the highest rating.

\section{Conclusions}

The intensive development of retail networks results in the perfection of the trade technology that is represented as an aggregate of works ensuring the performance of the trade process in the most rational ways in accordance with the specific economic conditions. Implementation of innovations enables the services of the retail networks to develop by means of efficient application of resources: capital renewals, improved operation of current assets, optimization of the circulation expenses, continuous personnel development, etc.

\section{References}

Antonchenko, N.G., Kalenskaya, N.V., Developing a methodology for assessing the efficacy of managerial decisions in entrepreneurial establishments// Life Science Journal (11) , Issue SPEC. ISSUE 7, 2014, pp. 365-369

Bekova, R. Distribution of new organizational forms and formation of competitive strategies of retail networks at Kazakhstan's food market Actual Problems of Economics 135 (9), 2012, pp. 238-244

Kalenskaya N.V., Khusnutdinov R.N., Grigoryeva L.L., Entrepreneurial networks management in the resource-based economic sector on the basis of institutional approach, Mediterranean Journal of Social Sciences.- Vol.5, No18, 2014. pp. 21-25.

Novikova, E., Beloborodova, A. An Assessment of the Efficiency of the Information System of Design-and-survey Organizations Based on the Analysis of the Information Capacity of Projects Implemented//World Applied Sciences Journal 29(1), 2014. pp. 20-25.

Valeeva, J., Sharafutdinova, N., Kulkova V. Quality management system's role in operation of retail trade networks// Life Science Journal 11(5), 2014. pp. 555-558

Ablaev I.M., Khovanskaya E.S. Essence and Economical Substance of Innovative Cluster in Territorially Localized Business System/l Mediterranean Journal of Social Sciences.- Vol.5, No12, (2014)-pp.159 - 162.

Varlamova J.A., Larionova N.I. Economic behavior of households: cross-country comparison. Life Science Journal 2014; 11(6s): 409413.

I.Sh. Khasanov, Three-sector structure of the national economy of Russia // Asian Social Science, Volume 10, 2014, Pages 217-224.

Vakhitova T.M., Gadelshina L.A. Directions of the region transport infrastructure development in the context of its competitiveness // Mediterranean Journal of Social Sciences vol. 5 № 24, November 2014, pp. 313-316. 